\title{
DE GOLPES E OUTRAS HISTÓRIAS: ECOS (ANTI) DEMOCRÁTICOS NA LITERATURA BRASILEIRA E ARGENTINA CONTEMPORÂNEA
}

\author{
POR \\ LEILA LEHNEN \\ Brown University
}

Em agosto de 2016, a presidente eleita Dilma Vana Rousseff foi cassada da presidência do Brasil, cargo que ocupava desde 2011 e para o qual foi reeleita em 2014. $O$ voto de 81 senadores a favor da cassação da $36^{\text {a }}$ presidente brasileira marcou o fim de catorze anos de presidência do PT (Partido dos Trabalhadores). Depois da cassação de Dilma, o seu vice, Michel Temer, do PMDB (Partido Movimento Democrático Brasileiro), assumiu o poder. Já desde sua interinidade (maio de 2016), a presidência de Temer deu sinais de que os avanços na área social e cultural implementados e fomentados desde a gestão do ex-presidente Luiz Ignácio Lula da Silva, iriam sofrer um retrocesso. $\mathrm{Na}$ área da cultura, o gesto emblemático foi a decisão de abolir o Ministério da Cultura (MinC) para reincorporá-lo ao Ministério da Educação (antigo MEC-Ministério da Educação e Cultura). O ex-vice presidente retrocedeu na decisão após fortes protestos de vários setores da sociedade brasileira, incluindo artistas conhecidos como Caetano Veloso e Seu Jorge.

$\mathrm{Na}$ área social, em outubro de 2016, a Câmara dos Deputados aprovou a Proposta de Emenda à Constituição (PEC) 241, que no Senado passou a se denominar PEC 55. A PEC do Teto de Gastos, como também ficou conhecida a proposta, apresentada pelo Ministro da Fazenda Henrique Meirelles, limita os gastos públicos por 20 anos, corrigidos apenas pela inflação do ano anterior. Desta forma, a PEC efetivamente congela os gastos públicos em áreas sensíveis como educação e saúde por um período de vinte anos. Segundo instituições como o Instituto de Pesquisa Econômica Aplicada (Ipea) e a Fundação Nacional de Saúde (FNS), a PEC 241 pode impactar negativamente as áreas da saúde, educação e assistência social. Em novembro de 2016 o senado aprovou a PEC 55 em primeiro turno com 61 votos a favor e 14 contra.

O impeachment da presidente Dilma Rousseff e as políticas implementadas desde seu afastamento pelo governo interino de Temer, sugerem que a chamada "onda [política] rosa" ("pink tide", "marea rosa"), que tomou conta de vários países latino-americanos entre 1999-2008, chegou ao fim no Brasil (Romero). 
Assim como no Brasil, a onda rosa também parece que chegou ao seu fim na Argentina com a eleição em 2015 de Mauricio Macri à presidência da república. Macri, candidato do partido de centro-direita Propuesta Republicana (PRO), deu fim a doze anos de governo peronista liderado pelos presidentes Néstor Kirchner e Cristina Fernández de Kirchner (2003-2007 e 2007-2015, respectivamente).

A onda rosa, da qual as presidências de Lula e Dilma, e dos governantes argentinos Néstor Kirchner e Cristina Fernández de Kirchner, foram talvez os governos mais emblemáticos, ${ }^{1}$ chegou como resposta à onda neoliberalizante que se impôs em vários países da região a partir das décadas de 1980 e 1990.

Se o neoliberalismo propõe a contenção dos gastos estatais-como argumenta David Harvey em A Brief History of Neoliberalism-e a ampliação do setor privado para incentivar o crescimento econômico, os governos pertencentes à onda rosa rejeitaram o dogma do Consenso de Washington, favorecendo um modelo político e econômico inspirado nas democracias sociais europeias (Painter). Vários dos governos de centroesquerda eleitos da esteira da onda rosa promoveram medidas de redistribuição de renda, destinadas a diminuir a profunda desigualdade social que assola a maioria dos países da América Latina. Nesta conjuntura, o estado retoma um papel central na administração social do país (Branford e Rocha 11).

Assim, muitos governos latino-americanos encabeçaram a implementação de uma série de programas de redução à pobreza, como a Bolsa Família no Brasil ${ }^{2}$ e o seu equivalente na Argentina, a Asignación Universal por Hijo (AUH), estabelecida durante o governo de Cristina Fernández de Kirchner em 2009.

Tanto no Brasil como na Argentina, estas medidas sociais são criadas paralelamente à continuação de políticas de incentivo ao setor privado e de disciplina fiscal. Em ambos os países, estas providências ajudaram na diminuição da desigualdade social. No Brasil, mais de quarenta milhões de pessoas entraram na classe média. A desigualdade social no país diminuiu em um terço, com o coeficiente Gini indo de 0,553 em 2002 a 0,500 em 2011. Apesar destes avanços (e subsequentes retrocessos), o Brasil continua sendo um dos países mais desiguais do mundo, ocupando o $16^{\circ}$ lugar globalmente. Da mesma forma, apesar de avanços na área social, da recuperação econômica do país após a crise de 2001 e a diminuição na taxa de pobreza, o índice de desigualdade social continuou

1 De acordo com Naomi Klein (The Shock Doctrine), o processo de implementação de um modelo neoliberal começa, na América Latina, com a ditadura de Augusto Pinochet (1973-1990) no Chile. Na Argentina, a junta militar que governou o país de 1976-1985, também começou a implementar certas medidas de cunho neoliberal. No entanto a junta argentina não chegou a instalar o sistema de forma tão contundente como no Chile.

2 O programa Bolsa Família tem seu antecedente nacional no programa Bolsa Escola, implementado em 2001 pelo governo de Fernando Henrique Cardoso. 
alto na Argentina, tendo crescido nos últimos anos. Dados recentes revelam que em 2019 35.4\% da população argentina vive na pobreza.

Em artigo no New Republic, Daniela Blei sugere que as causas do fim da onda rosa em países como o Brasil e a Argentina são, por um lado, o fim do crescimento econômico movido pelo boom de bens tais como petróleo e soja e, por outro, uma polarização da esfera política e uma paralela falta de credibilidade no processo eleitoral que se traduz em um desencanto com a política em termos mais amplos. Na Argentina, a candidatura de Macri capitalizou esta insatisfação. A coalização de partidos de centro-direita ${ }^{3}$ que apoiou a sua candidatura se apropriou da legenda "Cambiemos" para denotar o desejo de uma mudança de paradigma.

Segundo um estudo de 2015 realizado pelo instituto chileno Latinobarómetro, a América Latina é a região que apresenta o menor grau de satisfação com o sistema democrático. No Brasil, um levantamento realizado em setembro de 2016 pela Confederação Nacional da Indústria (CNI) demonstra que o governo Temer tem um índice de aprovação de apenas 14\% e de desaprovação de 39\%. O alto índice de votos em branco e abstenções nas eleições municipais de 2016 no Brasil também frisam o desencanto com o sistema democrático. Na Argentina, o governo Macri também apresenta um nível de aprovação semelhantemente baixo ao do governo Temer. Uma pesquisa realizada em 2016 pelo CEOP sobre o Índice da Satisfação da Cidadania (ISC) dá uma nota de 4 (em uma escala de 1-10) ao governo de Macri, sendo que são os jovens e os setores socioeconômicos mais baixos (Kollman) os mais descontentes.

Para o sociólogo português Boaventura de Sousa Santos o fortalecimento de um sistema capitalista, colonialista e patriarcal, leva ao enfraquecimento da democracia e ao surgimento do que ele denomina de "fascismo social". Para Sousa Santos este tipo de organização social acontece quando há uma concentração de poder nas mãos de determinados grupos. Sousa Santos associa o fascismo social com a precarização das condições sociais e, concomitantemente, com a erosão da cidadania substantiva(Santos).

Apesar ou talvez por causa da erosão da democracia substantiva, da contínua insatisfação das elites políticas e da implementação desigual e problemática do sistema democrático em muitos dos países latino-americanos, o que estudiosos chamam de democracia limitada ou incompleta (Kingstone e Power 6; Holston, "Citizenship" 77), podemos ver a recorrência de um vocabulário democrático na produção cultural destes países.

Segundo a antropóloga Teresa P. R. Caldeira, no Brasil, desde a transição democrática em 1985, houve uma popularização do vocabulário democrático-no seu sentido político, mas também dentro do âmbito social e da esfera cultural-. Protagonizado

A coalização foi formada em 2015 e é composta pelos partidos Propuesta Republicana, Unión Cívica Radical e Coalición Cívica.

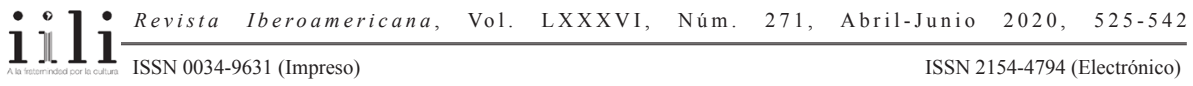


pelos movimentos sociais que foram instrumentais na formulação da Constituição de 1988, o discurso e o imaginário democrático foram apropriados pelos mais diversos setores da sociedade brasileira (Caldeira 10) e usados para promover diferentes metas sociais, tais como acesso à moradia, à saúde, à educação pública, etc.

Este vocabulário democrático não se limita aos setores políticos, sociais e civis, as três esferas da cidadania delineadas por T. H. Marshall em seu livro Citizenship and Social Class, mas se estende também ao cultural, revelando a imbricação entre a esfera política/social e a cultural nas recentes democracias latino-americanas. Evelina Dagnino propõe que após a transição democrática que vários países latino-americanos experimentaram nas décadas de 80-90 se estabeleceu uma nova noção de cidadania que incorpora várias facetas, incluindo o "papel das subjetividades, a emergência de sujeitos sociais de novo tipo e direitos de novo tipo e a ampliação do espaço da política" ("Cultura" 22).

A propagação do discurso democrático em suas diferentes vertentes (reivindicação de direitos sociais e de direitos humanos no sentido mais amplo do conceito) revela a associação que a socióloga Evelina Dagnino ("Cultura" 5) faz entre a propagação do vocabulário democrático e uma articulação do "direito a ter direitos" no período pós-transicional em várias democracias latino-americanas. A reivindicação de direitos reflete os ganhos sociais que parcelas significativas da população experimentaram após a efetivação de políticas redistributivas e a reversão do dogma neoliberal, ganhos estes que estão sendo revertidos à medida que o sistema democrático se fragiliza. Estes ganhos sociais abriram o caminho para uma visão mais igualitária das relações sociais (Dagnino, "Cultura" 27).

No entanto, como sugere Dagnino, a mudança de posicionalidade por parte de segmentos sociais tradicionalmente marginalizados também originou uma rejeição de setores dominantes que percebem estas demandas como uma "ingerência" dos seus privilégios não somente socioeconômicos, mas também como uma ameaça aos marcos de distinção que os identificam. O cientista político Leonardo Avritzer afirma que a integração de novos sujeitos à esfera do consumo resulta em uma rejeição destes participantes por parte de setores tradicionais. Avritzer mantêm que "o Brasil tem dificuldade em aceitar pressupostos igualitários do mercado. Isso se acentua ainda mais quando se fala em pressupostos de integração política ou mesmo de uma integração diferenciada no campo da educação. O centro desse processo está ligado a uma classe alta" (Avritzer, "As avenidas").

Os preceitos sociais hierarquizantes por sua vez irrompem numa nostalgia por políticas autoritárias, que mantenham ou então reafirmem o status quo. As manifestações a favor do afastamento da ex-presidente Dilma Rousseff e a demanda por uma volta da ditadura militar por parte de alguns setores da sociedade brasileira em 2015, assim como as ameaças legislativas aos direitos humanos supracitadas, são sintomáticas

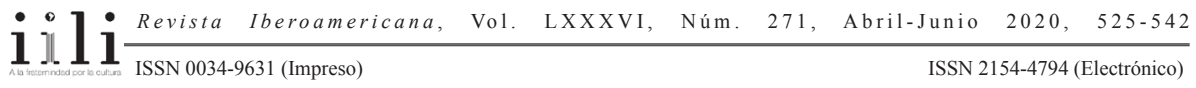


daquilo que o filósofo Jacques Rancière chama de “ódio à democracia”. Para Ranciére, o ódio à democracia advém de uma estrutura de poder que não sanciona um acesso amplo à democracia (Rancière 28), promovendo em vez disso uma organização social hierarquizante.

Refletindo estas tensões, há na literatura brasileira e argentina contemporânea uma variedade de textos que incorporam o vocabulário dos direitos e da cidadania de forma um tanto direta, como a modo de alusão à resistência a este léxico e às reivindicações que ele inculca. A presença deste vocabulário reflete as mudanças políticas e sociais no Brasil e na Argentina em décadas recentes, ao mesmo tempo que as problematiza.

Este ensaio indagará como o discurso democrático, assim como a representação da sua crise, se apresenta na literatura brasileira e argentina contemporânea. Propõe-se que o vocabulário democrático é um referente importante em ambas tradições literárias em anos recentes. Este vocabulário denuncia injustiças sociais, reivindica direitos, representa exercícios de apropriação da esfera pública e propõe meios de expansão de uma prática democrática ao campo da subjetividade. Ao mesmo tempo, o vocabulário democrático revela a tensão inerente à expansão de direitos e a transformação da cidadania em ambos os países. Especificamente, o ensaio considerará os "ecos democráticos" e antidemocráticos no romance Luxúria (2015), de Fernando Bonassi, e La noche de la usina (2016), de Eduardo Sacheri. Propõe-se analisar como as duas obras interpelam o conceito da democracia e sua prática, traduzindo-o para o âmbito simbólico.

Ambas obras literárias refletem, por um lado, a incorporação de um vocabulário democrático; por outro, este léxico é minado pela representação de práticas que promovem o que Holston chamou de "democracia disjuntiva". O "direito a ter direitos" que se articula em textos como Luxúria e La noche de la usina implica uma expansão de prerrogativas, mas também a erosão de uma sociabilidade devido ao fundamento autoritário que subjaz à apropriação de um código democrático num contex to neoliberal. Finalmente, os romances de Bonassi e Sacheri também expõem o dilema de estados que passaram a regimes democráticos durante aquilo que estudiosos denominaram de "terceira onda de democratização". ${ }^{4}$ Para Avritzer, os regimes democráticos da chamada "terceira onda", tais como o Brasil e a Argentina, demonstram uma discrepância entre um incremento nas ações coletivas democráticas dentro da esfera pública e

4 Em seu livro, The Third Wave: Democratization in the Late Twentieth Century, o cientista politico Samuel Huntington descreve uma "terceira onda" de transições e consolidações democráticas que ocorreram mundialmente depois da Revolução dos Cravos portuguesa (1974). Embora Avritzer use o termo (Avritzer, Democracy 5), ele discorda parcialmente das causas delineadas por Huntington para o fenômeno. Huntington identifica as elites nacionais como o motor da terceira onda de democratização e uma política de consenso empreendida por estas elites como uma das causas principais da consolidação democrática. Já Avritzer acredita que em países latino-americanos (Brasil, Argentina e México), regimes democráticos emergem da participação cidadã e não de pactos entre membros de uma elite nacional.

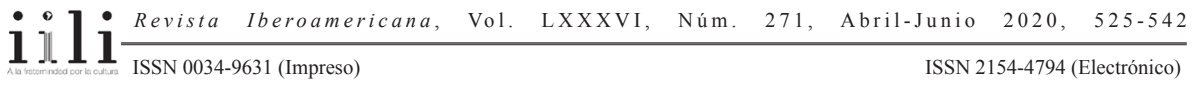


sua incorporação no âmbito político que, segundo Avritzer, continua a ter estruturas legadas dos recentes períodos autoritários. Avritzer explica que "in late democratization situations, tensions between an open, egaliatarian public space and a more closed and hierarchical political society may endanger democracy itself' (Avritzer, Democracy 6). Revelando os avanços da democracia e, ao mesmo tempo, o substrato autoritário que é subjacente às duas sociedades, os romances de Bonassi e Sacheri elucidam os dilemas da democracia brasileira e argentina na contemporaneidade.

\section{A LuXÚRIA (ANTI) DEMOCRÁTICA}

Luxúria, publicado em 2015, conta a história de um operário metalúrgico anônimo conhecido apenas como "o homem de que trata este relato". Impelido pelo ressentimento que sente em relação ao dentista da esposa, o protagonista decide construir uma piscina no fundo de sua casa. Como sugerem várias resenhas do romance e uma das epígrafes do texto ("Baseado em pessoas e acontecimentos reais, lamentavelmente"), ${ }^{5}$ o romance é uma alegoria da sociedade brasileira em anos recentes. Abordando a confluência entre o aparente fortalecimento da chamada nova classe média, representada pelo protagonista do romance, e a recente fragilização que segmento tem experimentado no decorrer da crise econômica brasileira, o romance de Bonassi evidencia um processo de democratização parcial, baseado principalmente na expansão do direito a consumir.

Os paralelos entre o livro e a realidade brasileira contemporânea ficam evidentes já no início do romance. Luxúria abre com a descrição de uma cidade em processo de crescimento vertiginoso-ainda que precário (Bonassi 9)-. Além da ideia de uma “prosperidade nacional", não há necessariamente uma lógica à expansão urbana descrita no romance. O ritmo acelerado de expansão urbana reflete o "momento histórico de prosperidade num país acostumado a viver na merda” (Bonassi 9). Esta máxima se repete ao longo da narrativa, parodiando um discurso nacional e internacional que até há pouco louvava o novo "milagre econômico" brasileiro. ${ }^{6} \mathrm{~A}$ ideia de "prosperidade nacional" é justaposta à fragilidade das construções. Este contraste aponta à debilidade do sistema econômico que cria o suposto "milagre", assim como a configuração social que se estabelece a partir deste panorama econômico. A voz narrativa sugere que o crescimento econômico ocasiona a expansão de direitos: "Os tempos negros foram ultrapassados. As pessoas têm direitos agora, como nunca sonharam antes” (Bonassi 77).

\footnotetext{
5 As outras duas epígrafes são de Karl Marx e da canção de Jimi Hendrix, "Drifting” (1971).

6 Ver por exemplo a antologia editada por Jan Neederveen Pieterse e Adalberto Cardoso, Brazil Emerging: Inequality and Emancipation, publicada em 2014. Na introdução ao volume, os organizadores classificam o Brasil como uma "economia emergente" afirmando que "Brazil ranks as a high-promise economy” (Pieterse e Cardoso 1).
}

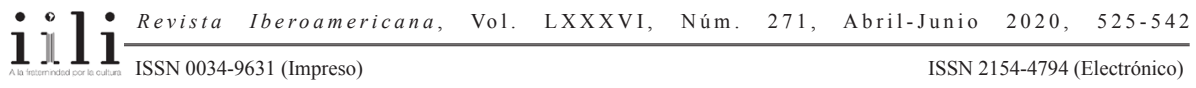


Luxúria enfatiza a relação entre a esfera econômica e da cidadania através do simulacro de ascensão social do protagonista. Esta ascensão está refletida na aquisição de bens materiais, entre eles a casa própria. $\mathrm{O}$ protagonista reside em um conjunto habitacional ironicamente chamado de "Bairro Novo". O Bairro Novo é uma alegoria do projeto nacional de democratização social que se baseou em grande parte em medidas de redistribuição econômica e de incentivo fiscal, como o programa Minha Casa, Minha Vida. Assim, o marketing do conjunto habitacional evoca a campanha de publicidade do programa habitacional do governo federal lançado em 2015 com o slogan: "Minha Casa Minha Vida. Mais que mudar de endereço, é mudar de vida". Semelhantemente, a propaganda do Bairro Novo sugere que as casas do conjunto representam o sonho imobiliário da família nacional (Bonassi 23).

Entretanto, ao contrário do que promete o nome e o anúncio, o "Bairro Novo" não oferece aos seus habitantes uma inserção dentro de um espaço urbano e/ou social renovado. Em vez disso, o conjunto habitacional popular "tinha se perdido no tempo e no espaço. Não se encontra nem nunca se encontrou no centro de algo importante. [...] Entregara os pontos ao progresso que voava em torno" (Bonassi 22-23). O conjunto se situa dentro de um limbo entre a promessa de uma melhoria social e os limites destas transformações. As casas do subúrbio são pequenas e estão construídas muito próximas umas às outras ("Estamos cercados" [Bonassi 41], ênfase no original), sugerindo um espaço geográfico e social circunscrito, limitado. A justaposição entre a acessibilidade das casas populares e a sua precariedade revela, por um lado, a expansão democrática e, por outro, a fragilidade deste modelo democrático, que se limita à esfera do consumo. ${ }^{7}$

Como a cidade em expansão, o Bairro Novo tambémé caracterizado por edificações precárias, com espaços públicos dilapidados e casas pequenas onde as famílias vivem um simulacro de ascensão social representada pela posse do imóvel e de outros marcos de distinção pequeno-burguesa, como o carro próprio. O antropólogo James Holston (Insurgent 9) propõe que, na esteira da redemocratização do país e da reformulação legislativa de 1988, a posse de um imóvel para residentes das periferias brasileiras muitas vezes passou a conotar a obtenção de direitos sociais e civis. A partir da propriedade privada e do direito à cidade que este privilégio outorga, os moradores de bairros periféricos se estabelecem como cidadãos de direitos. No entanto, à medida que residentes periféricos vão assegurando seus direitos, se instauram novas formas de conflito que visam reestabelecer ou criar novas hierarquias. No caso dos residentes do Bairro Novo, a ideia de cidadania se expressa em uma sociabilidade baseada na vigilância "democrática" que, por sua vez, "mantém a ordem e o estímulo invejoso que move a indústria, e que gera empregos. A maioria pode comprar" (Bonassi 43;

\footnotetext{
Em um ensaio recente, o filósofo Achille Mbembe associa a erosão da democracia liberal com o avanço
} renovado do capitalismo neoliberal (Mbembe, “The Age of Humanism”).

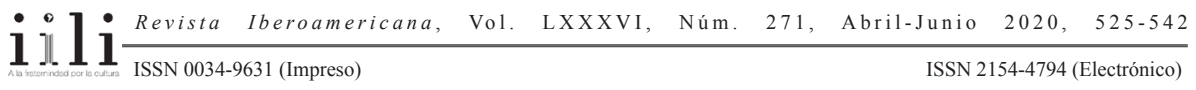


ênfase no original). A vigilância, aliada ao incentivo ao consumo, são caracterizados como os pilares da ordem social democrática ("a maioria") que cria uma aparente igualdade através do consumo.

Segundo Marilena Chauí, a fragilidade da democracia brasileira reside na deficiência dos direitos sociais dos cidadãos. Chaú argumenta que:

Democracy is a form of social existence. Therefore, only a democratic society can forge a democratic political regime. As a social institution, democracy defines citizenship through the idea of social, civil, economic, and cultural rights. Now, Brazilian society is polarized between privilege and poverty, and, therefore, the difficulty of implementing democracy in Brazil stems from the social absence of the dimension of rights. (51)

No romance de Bonassi, as referências às políticas de benefício social como o sobrecitado Minha Casa Minha Vida são justapostas à inconsistência desta integração social e à expansão de direitos sociais principalmente no tangente ao sistema público de saúde e de educação. A precariedade destas duas instituições aponta a outros diferenciais dos direitos sociais.

Através da representação das deficiências do ensino público e do sistema de saúde pública, Luxúria questiona o modelo limitado de cidadania econômica. Este paradigma não aborda a desigualdade dos direitos sociais tais como educação e assistência médica. No romance, o sistema de saúde público é descrito como uma instituição onde a burocracia é combinada à ineficiência. A escola do filho do protagonista é o cenário de múltiplas violências, onde impera o descaso e a incompetência. Esta representação revela o descaso com o ensino público e seus beneficiários. Apesar das altas taxas de escolaridade no país, a educação pública no Brasil apresenta um alto índice de improdutividade, como descrito por Lorena Freitas (298). A inadequação das escolas públicas consolida hierarquias sociais.

$\mathrm{O}$ romance frisa a equivalência entre o direito à educação e o posicionamento social através do confronto, simbolizado pela piscina, entre o protagonista e o dentista da esposa. Para o protagonista de Luxúria, a piscina representa uma reivindicação ante o dentista da classe média tradicional e dos símbolos de distinção que salientam uma configuração social hierárquica e excludente e, portanto, antidemocrática (Chauí 169). Ao ver os marcos de distinção do dentista, títulos universitários que o identificam claramente como um membro da classe média tradicional, o protagonista se sente "envenenado e oprimido [...], pela intimidade que o dentista consegue com os outros, pela limpeza das roupas que ele veste, pelos 'sonhos' que ele tem" (Bonassi 17), enquanto que ele "é o que se suja todo dia, o que rasteja, passa por baixo" (Bonassi 17). A justaposição entre a "limpeza" do dentista e a condição "suja" do protagonista simboliza a consciência da sua exclusão (apesar dos aparentes avanços econômicos da classe a que o protagonista pertence) e o discernimento da injustiça de tais distinções.

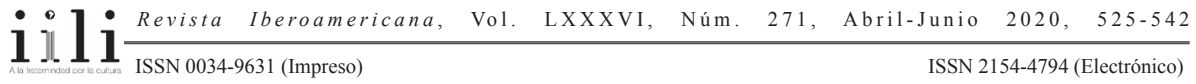


O protagonista do romance de Bonassi inconscientemente entende que sua inserção social se dá por meio dos "capitais impessoais", tais como a educação, que facilitam seu "acesso privilegiado a literalmente todos os bens (materiais ou ideais) ou recursos escassos em uma sociedade de tipo capitalista moderna" (Souza 48). Ele, por sua vez, está excluído deste horizonte de oportunidades pela falta de capital cultural (Souza 49). A piscina sugere a possibilidade de questionamento destes parâmetros e apropriação de um capital simbólico que permitiria ao protagonista transgredir os limites de seu estado social.

Sendo assim, pode-se interpretar a animosidade do homem frente ao dentista e seus diplomas como uma reivindicação implícita do direito a ter direitos-ainda que estes direitos se traduzam principalmente na esfera da aquisição de bens de consumo-. Esta premissa é comunicada claramente pelo vendedor de piscinas que, ante a hesitação do protagonista em efetuar a compra, afirma enfaticamente que "você tem direito a bem-estar!" (Bonassi 69).

No romance, as repetidas menções a hipotéticos direitos (de compra e venda, de crediário) revelam, ainda que de forma deturpada, a expansão de uma consciência democrática a âmbitos para além do estritamente político. Neste sentido, a construção da piscina representa, para o protagonista, não somente uma forma de inclusão social que contesta hierarquias tradicionais, mas também uma proposta de subjetividade e de autonomia.

Assim como a impotência frente à posição social superior do dentista da esposa se manifesta de forma física (dor de cabeça, azia [Bonassi 17]), a sua suposta autonomia também assume uma expressão física. Ao receber as primeiras faturas da piscina, o homem sente um "certo vigor", "Um troço viril até!” (Bonassi 138-39; ênfase no original). A citação transmite a ideia de domínio e de ação. Ou seja, através da construção da piscina, o protagonista acredita que pode alcançar um grau de emancipação da sua condição social restrita ("Eu tenho poderes. Com licença" [Bonassi 18, ênfase no original]), assim como de um estado ontológico circunscrito.

O desejo de afirmação social e pessoal cobra um significado mais amplo se consideramos que o protagonista tem sua autonomia restringida em âmbitos que cruzam as fronteiras entre o existencial e o social. Isto é particularmente evidente na esfera laboral. O protagonista trabalha em uma fábrica de peças mecânicas. Sua ocupação é descrita como tediosa e opressiva: "Quando o homem entra na fábrica, o relógio engasga. O tempo para. Anda para trás" (Bonassi 33). A natureza repetitiva do trabalho transforma os operários em peças na engrenagem de produção, anulando sua subjetividade, ou limitando-a.

Todavia, apesar do caráter maçante e opressivo, para o protagonista e seus colegas, o trabalho representa um dever, a disciplina da sua posição social (Souza 48) e até mesmo uma forma de identificação pessoal e social. Como dizum dos ex-companheiros

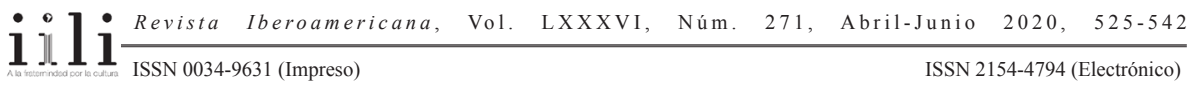


de trabalho do protagonista que perdera o emprego: "Quando você tem alguma coisa para fazer, qualquer coisa, você também é feito pela coisa que faz e está tudo bem. O pouco que eu era, era o emprego que eu tinha, e já nem sei o que não fazer" (Bonassi 326). Souza afirma que o trabalho "disciplinado e regular" (Souza 52) outorga ao trabalhador da classe média emergente uma legitimidade social. Através do seu ofício, ele/ela "contribui" para a sociedade. Neste papel, ele/ela é um sujeito de direitos, ainda que estes sejam limitados. A inserção no mercado de trabalho também insinua um horizonte de ascensão social. Ou seja, o trabalho garante ao trabalhador uma identidade social no presente e no futuro. Ao desaparecer este marco de identificação, o trabalhador perde não somente os seus referenciais pessoais, mas se transforma em uma espécie de pária social.

Luxúria, no entanto, revela a fragilidade desta proposta e, concomitantemente, dos direitos associados a este projeto, no contexto de uma economia global que valoriza sobretudo a eficácia e a lucratividade do processo de produção. Desde as últimas décadas do século vinte, o modelo de produção fordista que impulsionava importantes segmentos da economia dá lugar a outros tipos de modelos de produção. Como indica Jessé Souza, por um lado valoriza-se a inovação e a eficiência (Souza 55).

No romance de Bonassi, esta transformação é tipificada, por um lado, pelo sistema de vigilância que visa aumentar a produtividade dos trabalhadores e, por outro, pela mecanização do processo de produção, também com o intento de incrementar a produção. A introdução de uma máquina que pode produzir "uma peça por minuto" (Bonassi 281) revela a valorização do rendimento produtivo assim como a natureza descartável do trabalho operário. O romance posiciona esta lógica dentro da aceleração econômica descrita pela narrativa. Há uma correlação entre a ideia de "progresso" (repetida no mote do "momento histórico de prosperidade") e da transformação do sujeito em objeto destinado a produzir e a consumir: "O MOMENTO HISTÓRICO de prosperidade também impõe desafios enormes para as máquinas de produção públicas e privadas, tudo (vivo ou inanimado) opera nos limites. O ócio (de tempo ou de espaço), quando existe, é rapidamente medido, financiado e adquirido" (Bonassi 31).

Luxúria se apropria do vocabulário social, econômico e político que dominou a esfera pública brasileira nos últimos anos para problematizar a ideia da inclusão democrática. O romance sugere que a linguagem de direitos está associada a uma racionalidade neoliberal que, em última instância, mina este linguajar e, consequentemente, o ideal democrático delineado na Constituição de 1988. Segundo o prâmbulo deste documento, o estado brasileiro tem como sua raison d'etre, "o desenvolvimento, a igualdade e a justiça".

Dagnino ("Citizenship" 550) aponta à confluência da linguagem de direitos e de uma racionalidade neoliberal que se faz presente em países como o Brasil a partir dos anos 90. Para ela, houve em vários países latino-americanos, depois de um momento

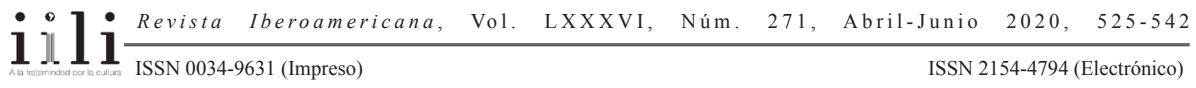


inicial de democratização, uma cooptação, por parte de uma lógica neoliberal, dos movimentos sociais e do discurso por direitos que estes articularam. Esta confluência perversa, nas palavras de Dagnino, legitimou a retração do estado de bem-estar social e a prevalência de um modelo social e econômico neoliberal.

Se no romance de Bonassi vemos como a predominância desta racionalidade neoliberal leva a uma crise pessoal, metáfora de uma crise social, no texto do escritor argentino Eduardo Sacheri, La noche de la Usina, a ideologia neoliberal tem como consequência a crise da nação e a formação de comunidades de solidariedade alternativas ao estado nação. O romance de Sacheri aponta assim aos limites do estado democrático como comunidade que beneficia todos os seus cidadãos.

\section{O LONGO OCASO DO NEOLIBERALISMO}

La noche de la Usina, vencedor do premio Alfaguara de romance 2016, conta a história de um grupo de amigos que, ao perderem o dinheiro que haviam guardado para um investimento durante o corralito de 2001, ${ }^{8}$ resolve tomar a justiça em suas próprias mãos. Além de ser um retrato da crise econômica e política argentina do começo do século XXI, o romance de Sacheri por um lado alegoriza o falho da democracia visà-vis a culminação de políticas neoliberais e, por outro, representa uma espécie de reinterpretação do seu significado resultado da crise que minou os preceitos do estado democrático argentino.

A narrativa de La noche de la Usina abre-se com uma alusão nostálgica a um passado nacional onde o horizonte de futuridade ainda era possível. O povoado onde se desenvolve a trama do romance, O'Connor, vive da recordação de uma época melhor, ainda que imprecisa. É o retrato de uma Argentina da virada do século, quando o país era o décimo mundialmente em renda per capita. As frases iniciais do livro lembram as linhas de abertura de um conto de fadas, aludindo a uma mitologia nacional do progresso e da inclusão social decorrente deste. O caráter mitológico deste "tempo de progresso" é realçado pela imprecisão da descrição cronológica e espacial da descrição:

Dicen los viejos que hubo un tempo en que las cosas andaban bien en O'Connor, aunque les cuesta mucho ponerle fecha a esa época de abundancia. "Acá...," dicen con un gesto amplio de la mano que señala las casas y el campo alrededor, hasta el horizonte, "No sabés...," agrega, sin mayores precisiones. Pero esperan que quien los escucha sí sepa, que entienda que se refieren a un tempo en que todo era progreso. (Sacheri 17)

8 Corralito foi o nome dado ao pacote de medidas econômicas tomadas em dezembro de 2001 pelo ministro da economia Domingos Cavallo. As contas bancárias foram congeladas e suspenso o saque de dinheiro em dólares, a menos que o titular da conta convertesse os dólares em pesos. O objetivo do corralito era interromper a saída de divisas do país.

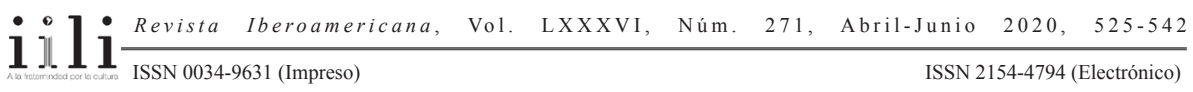


As elipses na descrição comunicam a ideia de uma perda. Ao contrário do sugerido pela descrição incompleta dos "velhos", a nostalgia e a desolação impregnam a paisagem presente do vilarejo, que se transforma em uma alegoria do panorama nacional. Na opinião de Fermín Perlassi, um dos personagens principais do romance: "el país se va a la mierda" (Sacheri 23).

Em contraste com a imprecisão de um passado melhor, o tempo da narrativa tem um referente concreto: a crise econômica e política que avassalou a Argentina em $2001 \mathrm{e}$ que tem suas origens na neoliberalização do país efetivada baixo a presidência de Carlos Saul Menem (1989-1999). Após um breve período de recuperação econômica entre 1996-98, em 2001 o país entrava no seu terceiro ano de recessão. Com a equivalência entre o peso e o dólar, implementada em 1992, as exportações argentinas perderam a competitividade no mercado internacional. Ao mesmo tempo, a equiparação do peso fez com que o mercado nacional fosse inundado por produtos importados, levando à crise da indústria doméstica e ao aumento do desemprego. Temendo o colapso econômico e uma possível desvalorização do peso, muitos argentinos retiraram dinheiro das suas contas e/ou converteram seu patrimônio de peso a dólares.

A contextualização do romance de Sacheri sinaliza não somente a crise econômica do país, mas também uma concomitante erosão da soberania nacional desde a presidência de Menem. Em 1999, o governo do presidente Fernando de la Rúa, respondendo a demandas do Fundo Monetário Internacional, passou medidas de austeridade em meio de taxas de desemprego de até $14 \%$. Segundo Chauí, dentro do contexto de regimes neoliberais, o estado deixa de representar os interesses dos cidadãos para atender as exigências de organizações supranacionais, tais como o Banco Mundial ou o Fundo Monetário Internacional (49).

La noche de la Usina alude à quebra do contrato social e ao colapso de um espaço de direitos para os cidadãos através da representação de O'Connor como uma cidade estagnada, com poucas oportunidades de emprego e um horizonte futuro constrito. Os habitantes da cidade têm em comum a pobreza e o fracasso (Sacheri 17). São pessoas que estão fora do projeto nacional. O'Connor representa um território literal e simbolicamente marcado pelo abandono. Assim por exemplo, as obras públicas para evitar a inundação da região iniciadas durante o governo do presidente Raúl Alfonsín (1983-1986) são abandonadas devido a medidas de austeridade (Sacheri 29). O que resta das obras são ruínas. As ruínas são uma imagem recorrente dentro do romance. Elas são alegorias do fim de um projeto de desenvolvimento e de inclusão social.

O romance associa o abandono da empreitada com o fim do governo de Raúl Alfonsín. Como primeiro presidente após a transição democrática de 1983, Alfonsín representa tanto a promessa da democracia como o seu fracasso. Durante os primeiros dias no cargo, o ex-presidente tentou implementar medidas de justiça transicional ao abolir a lei da anistia implementada pelo governo militar de Rodolfo Bignone. Esta

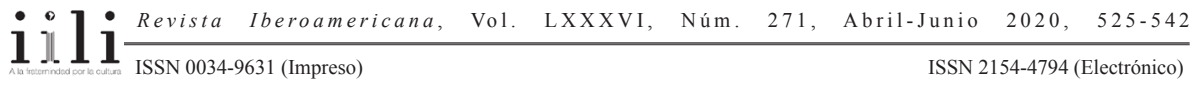


legislação foi anulada pela Ley de Punto Final (1986) e a Ley de Obediencia Debida (1987). A rescisão de julgamentos aos responsáveis pelas violações de direitos humanos durante a ditadura no governo Alfonsín revela o limite dos movimentos sociais que foram instrumentais na implementação da democracia na Argentina e no estabelecimento de um vocabulário democrático no país.

No âmbito econômico, Alfonsín implementou o Plano Austral (1984), que combinava providências de estímulo econômico, como o aumento dos salários, com medidas de austeridade fiscal tais como a diminuição dos gastos públicos. Segundo Ronaldo Munck, o fracasso do Plano Austral abalou a crença nas instituições democráticas e abriu o caminho para a política neoliberal implementada pelo governo de Menem(72). O governo deste último se caracterizou por uma erosão das instituições democráticas e o incremento da corrupção do poder executivo.

O desencanto com o sistema democrático que se aprofunda durante a presidência de Menem continua mesmo depois do fim de seu governo. Assim, durante as eleições de 2001 o número de votos em branco foi significativo (Munck 75). Em La noche de la Usina, a trajetória nacional do otimismo pós-transicional ao desencanto político é conotada pela admiração nostálgica do engenheiro Antonio Fontana pelo ex-presidente Alfonsín. Fontana associa a administração de Alfosín com um "projeto de pátria" de uma "democracia burguesa" que abrirá caminho a um "futuro libertário" (Sacheri 29). Para Fontana, o vocabulário democrático excede o âmbito das instituições políticas e inclui um imaginário utópico. Assim sendo, Fontana vê em Alfonsín o último representante do estado democrático argentino ("Hasta que Alfonsín sea presidente de nuevo, no se puede confiar en el Estado" [Sacheri 438]). No entanto o simbolismo é ambíguo já que o governante representa por um lado a consolidação da democracia no país e por outro seu enfraquecimento pelo descrédito do estado como gerenciador do bem-comum.

$\mathrm{O}$ romance de Sacheri alude à colusão entre política e economia que leva ao desencanto democrático, ao revelar que um dos homens de negócio da região, Fortunato Manzi, consegue aumentar seus negócios ao subornar as autoridades locais (Sacheri 85). Manzi é o anti-herói do romance. Sua subjetividade se constrói a partir da sua luta por aumentar o seu patrimônio. Seu vocabulário, que inclui frases feitas como "Hay que ser inteligente y precavido" (Sacheri 142) e "Conocer es anticiparse" (149), revela o conceito de uma subjetividade "empreendedora de si". Segundo Tatiana Roque, trata-se de "um tipo subjetivo que facilita a adesão às formas de sociabilidade contemporâneas, fundadas na concorrência e no sucesso individual" (Roque). O enfoque no successo individual culmina quando Manzi, ajudado pelo gerente do banco local, Alvarado, roubam o dinheiro que Perlassi e um grupo de homens de O'Connor tinham juntado para comprar a defunta avícola La Metódica.

Aproveitando a eminência do corralito, os dois homens conspiram para efetivamente roubar o depósito de dinheiro feito pelos sócios para a compra da cooperativa. Com a conivência de Alvarado, Manzi retira a quantia do banco e guarda-a em um cofre

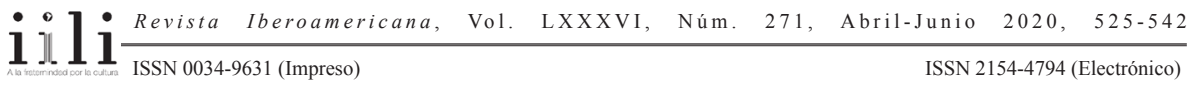


subterrâneo. O embuste arquitetado entre Manzi e Alvarado serve como metáfora da erosão do controle do estado sobre a esfera econômica e as consequências desta desregulação.

Para Chauí, o neoliberalismo como ideologia de estado e mandato social reduz o âmbito dos direitos democráticos, ao outorgar mais privilégios aos interesses do mercado (49). Há assim uma erosão do sistema democrático e uma transformação deste em uma ordem social e política financeirizada. Em La noche de la Usina, a crise do estado democrático-representada pelo corralito-é possibilitada e perpetua um sistema de exploração econômica.

A solução a este ciclo ocorre fora do âmbito do estado. La noche de la Usina retrata a crise do sistema democrático a partir da ausência, ou da incompetência, do estado. Não há a possibilidade de retificação legal para os sócios da cooperativa. Para obter justiça e recuperar seus investimentos, o grupo liderado por Perlassi e Fontana decide arrombar o cofre subterrâneo de Manzi, onde este guarda o espólio roubado dos sócios. Grande parte do romance se centra no esforço do bando de Perlassi e Fontana de recuperar os seus investimentos. É um esforço coletivo que abarca vários "setores" da sociedade de O'Connor-desde o bem-sucedido negociante Franscico Lorgio-até o "viejo" Medina, que vive sob permanente ameaça de ser desalojado de seu sítio. A operação é um gesto de resistência que se vale da transgressão para fazer valer os direitos dos membros do grupo.

Dentro do contexto de crise que anula o potencial de futuridade para aqueles sujeitos que estão às margens do projeto neoliberal, a esperança que resta aos habitantes de O'Connor é o campo. Falando com sua esposa, Perlassi observa que: "Cuando se vaya todo a la mierda, Silvia. El campo va a quedar" (Sacheri 23). A referência ao "campo" como tábua de salvação remete a um tempo anterior ao estado-nação neoliberal. O campo é uma espécie de utopia possível, a volta a uma sociabilidade mais democrática. A rejeição de um modelo de governança dominando pelos interesses do mercado é reforçada na articulação do plano de Perlassi e seu melhor amigo, o chefe de obras Antonio Fontana, de enfrentar a crise econômica estabelecendo uma cooperativa agrícola na defunta avícola La Metódica.

Além da obra pública abandonada, dos diferentes negócios em decadência (como por exemplo o posto de gasolina de Perlassi) e de um estado agonizante, La Metódica é a ruína mais significativa no livro de Sacheri. Após um começo promissor, o negócio vai à falência ironicamente por causa de seu sucesso que engendra outros empreendimentos semelhantes, diminuindo os preços da carne de frango na região (Sacheri 35). A ruína da avícola representa o fracasso de um projeto de modernização capitalista que atinge seu auge na onda neoliberal dos anos 90 e princípios dos anos 2000. Sua transformação em um espaço de uma possível futuridade e de participação democrática é, portanto, significativa.

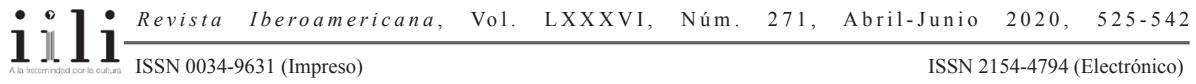


O plano dos amigos de transformar a ruína da avícola em uma cooperativa evoca a ocupação de negócios falidos que começou no país nos anos 90 em resposta à crise financeira e que intensificou depois de 2001. Tais como os negócios ocupados pelos funcionários desempregados, a cooperativa fornece aos habitantes de O'Connor uma alternativa ao padrão neoliberal que provocou a erosão do contrato social. Ao contrário do modelo neoliberal adotado pelo estado argentino nos anos 90, a lógica da cooperativa de $\mathrm{O}^{\prime}$ Connor não está sujeita à primazia do lucro e sim a da partilha e da responsabilidade social ("les damos trabajo a unos cuantos, con eso" [Sacheri 26]).

Podemos interpretar a empreitada de Perlassi e seus associados, tanto de reaver o dinheiro roubado como de criar a cooperativa, como uma alegoria de uma mobilização social que ocorre paralela às instituições públicas (neste caso, a corte) e que, segundo Avritzer, foi um percussor da consolidação democrática em países como a Argentina e o Brasil. Assim, pode-se ler a operação do grupo como uma afirmação de uma cidadania através do que Engin Isin e Greg Nielsen chamam de "atos de cidadania" (Isin e Nielsen 10), ações que transformam indivíduos em sujeitos de direitos. Estes atos, segundo eles, podem ser transgressivos e, pelo tanto, podem estar em oposição ao sistema legal. Desta forma, o ato de cidadania executado pelos sócios opera tanto segundo uma lógica democrática (a ideia da "igualdade de dignidade" e de direitos que o sistema democrático pressupõe [Holston, "Citizenship" 88]) como através da sua aparente transgressão: a recuperação "ilegal" do dinheiro roubado.

\section{CONClusão}

No dia 29 de novembro de 2016, o jornal norte-americano The New York Times publicou um artigo sobre a crise da democracia no mundo atual (Taub). Segundo a autora do ensaio, após um extenso período de consolidação, ${ }^{9}$ a democracia como sistema político aparenta estar entrando em crise. Recentes desenvolvimentos políticos no Brasil e na Argentina, tais como o afastamento da presidente eleita Dilma Rousseff ou os impedimentos que o governo de Mauricio Macri está impondo sobre a paridade de gênero nas listas de candidatos a eleições, sugerem uma erosão do sistema da democracia participativa.

Os textos literários aqui analisados ora auguram essa crise da democracia, ao demonstrar os limites impostos sobre ela pela prevalência de uma lógica neoliberal, ora traçam um quadro de comunidades e redes de solidariedade que não mais estão atrelados à nação de forma simbiótica (La noche de la Usina) e que, de certa forma, preenchem

9 Caldeira e Holston, tomando como referência a informação compilada pela Freedom House, indicam que entre 1972-1996 houve um acréscimo de 66 novas democracias eleitorais mundialmente, um aumento de $62 \%$ nos países com este tipo de sistema político.

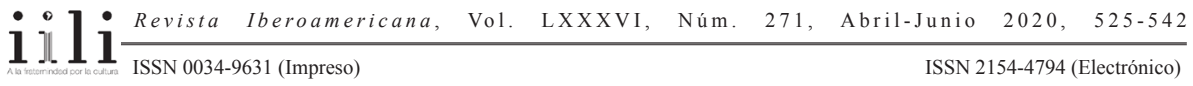


o vácuo das democracias disjuntivas. Ambos romances refletem uma incorporação do vocabulário democrático através da articulação de sua crise. No caso de Luxúria, o padrão de democracia sugerido na narrativa está ligado ao consumo que outorga cidadania e que a oblitera uma vez que o indivíduo não pode cumprir com os parâmetros de consumo impostos. O romance de Bonassi expõe uma contradição fundamental entre a noção de direitos propagada dentro da democracia e sua implementação, sugerindo a prevalência de um modelo democrático disjuntivo (Holston, "Citizenship" 90). Em La noche de la Usina, o vocabulário democrático se manifesta na criação de uma cooperativa agrícola que aborda a crise gerada por um estado ausente, criando a possibilidade de direitos básicos como o direito ao trabalho remunerado que, em teoria, são garantidos por este estado. Há no livro de Sacheri uma proposta de um modelo de maior participação democrática, embora esta se dê paralelamente ou em oposição à instituições democráticas que deveriam assegurar o exercício da cidadania. Sendo assim, há uma indagação da efetividade do modelo democrático.

\section{OBRAS CITADAS}

Avritzer, Leonardo. "As avenidas de inclusão no Brasil e uma disputa política intensa. Entrevista especial com Leonardo Avritzer". Entrevista por Márcia Junges. IHU On-line (2016).

Democracy and the Public Space in Latin America. Princeton: Princeton UP, 2002.

Blei, Daniela. "Is the Latin American Left Dead?" New Republic online edition (18 abril 2016). <https://newrepublic.com/article/132779/latin-american-left-dead $>$. 20 abril 2016.

Bonassi, Fernando. Luxúria. Rio de Janeiro: Record, 2015.

Branford, Sue, y Jan Rocha. Brazil Under the Workers' Party: From Euphoria to Despair. Rugby: Practical Action Publishing, 2015.

Caldeira, Teresa P. R. Espacio, segregación y arte urbano en el Brasil. Claudia A. Malmierca de Solans, trad. Buenos Aires: Katz, 2010.

y James Holston. "Democracy and Violence in Brazil." Comparative Studies

in Society and History 41/4 (1999): 691-729.

Chaú, Marilena S. Between Conformity and Resistance: Essays on Politics, Culture, and the State. New York: Palgrave Macmillan, 2011.

Dagnino, Evelina. "Citizenship: A Perverse Confluence." Development in Practice 17/4-5 (2007): 549-56.

y otros. "Cultura democrática e cidadania". Opinião Pública 5/1 (1998): 20-71.

Freitas, Lorena. "A instituição do fracasso". A ralé brasileira: Quem é e como vive. Jessé Souza, ed. Belo Horizonte: Editora UFMG. 281-304.

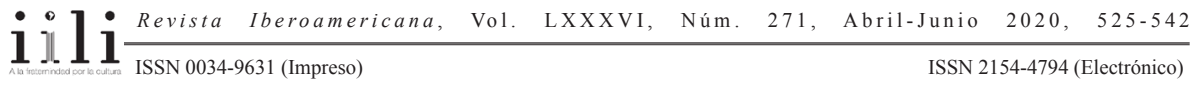


Harvey, David. A Brief History of Neoliberalism. Oxford: Oxford UP, 2005.

Holston, James. Insurgent Citizenship: Disjunctions of Democracy and Modernity in Brazil. Princeton: Princeton UP, 2008.

"Citizenship in Disjunctive Democracies." Citizenship in Latin America. Joseph

S. Tulchin y Meg Ruthenburg, eds. Boulder: Lynne Rienner, 2006. 75-94.

Huntington, Samuel P. The Third Wave: Democratization in the Late Twentieth Century.

Norman: U of Oklahoma P, 1991.

Isin, Engin F. e Greg M. Nielsen, eds. Introducción. Acts of Citizenship. New York: Palgrave Macmillan, 2008. 1-12.

Kingstone, Peter R. y Timothy J. Power, eds. Introducción. Democratic Brazil Revisited. Pittsburgh: U of Pittsburgh P, 2008. 1-12.

Klein, Naomi. The Shock Doctrine: The Rise of Disaster Capitalism. New York: Metropolitan Books/Henry Holt, 2007.

Kollman, Raúl. "Dos ricos, pelos ricos e para os ricos". Carta Maior. Victor Farinelli, trad. 21 nov. 2016. <http://cartamaior.com.br/?/Editoria/Internacional/Dos-ricospelos-ricos-e-para-os-ricos/6/37294>. 23 nov. 2016.

Marshall, T. H. Citizenship and Social Class and Other Essays. Cambridge: Cambridge UP, 1950.

Mbembe, Achille. "The Age of Humanism is Ending." Mail and Guardian. 22 dez. 2016. <http://mg.co.za/article/2016-12-22-00-the-age-of-humanism-is-ending>. 15 dez. 2016.

Munck, Ronaldo. "Argentina, or the Political Economy of Collapse." International Journal of Political Economy 31/3 (2001): 67-88.

Painter, James. "South America's Leftward Sweep.” BBC News. 2 marzo 2005. < http:// news.bbc.co.uk/2/hi/americas/4311957.stm>. 17 de sept. 2016.

Pieterse, Jan Nederveen y Adalberto M. Cardoso, eds. Introducción. Brazil Emerging: Inequality and Emancipation. New York: Routledge, 2014. 1-10.

Rancière, Jacques. Hatred of Democracy. London: Verso, 2006.

Romero, Simon. "Is Leftist Era Fading in Latin America? Ask Colombia and Brazil." New York Times. 3 out. 2016. <https://www.nytimes.com/2016/10/04/world/ americas/latin-america-colombia-brazil.html?_r=0>. 10 out. 2016.

Roque, Tatiana. "Por uma Esquerda capaz de disputar a subjetividade". Outras mídias 8 fev. 2017. <http://outraspalavras.net/outrasmidias/destaque-outras-midias/poruma-esquerda-capaz-de-disputar-a-subjetividade/>. 10 fev. 2017.

Sacheri, Eduardo A. La noche de la Usina. Madrid: Alfaguara, 2016.

Santos, Bonaventura de Souza. "A democracia que temos não tem futuro. Entrevista com Boaventura de Sousa Santos". Entrevista por Sarah Fernandes. IHU On-line (2017). <http://www.ihu.unisinos.br/563765-a-democracia-que-temos-nao-temfuturo-entrevista-com-boaventura-de-sousa-santos>.15 jan. 2017.

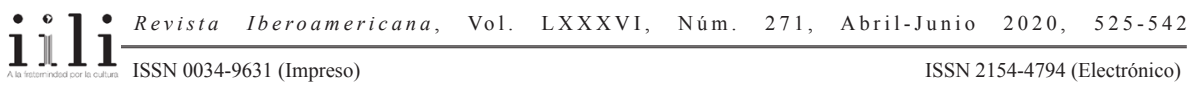


Souza, Jessé. Os batalhadores brasileiros: nova classe média ou nova classe trabalhadora? Belo Horizonte: Editora UFMG, 2012.

Taub, Amanda. "How Stable Are Democracies? 'Warning Signs Are Flashing Red'." New York Times. 29 nov. 2016. <https:/www.nytimes.com/2016/11/29/world/ americas/western-liberal-democracy.html>. 29 nov. 2016.

Palavras-chave: Democracia; Fernando Bonassi; Luxúria; Eduardo Sacheri; La noche de la Usina

Recebido: $\quad 15$ novembro 2016

Aprovado: $\quad 15$ maio 2017

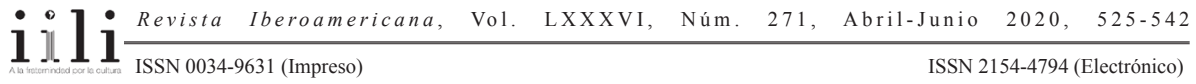

